\title{
Dexamethasone treatment for acute bacterial meningtitis: how strong is the evidence for routine
} use?

Kameshwar Prasad, Ted Haines

\begin{abstract}
A methodological appraisal of the published randomised controlled trials on the use of dexamethasone as an adjunct treatment in acute bacterial meningitis was carried out to examine whether the available evidence is strong enough to support the routine use of the drug.

Studies were eligible for inclusion if they were published in indexed journals after 1966, written in English, and were randomised controlled trials with dexamethasone as adjunct to antimicrobials in patients with acute bacterial meningitis. All studies were extracted and their adherence to eight methodological principles was graded as adequate, inadequate, or unclear. A sensitivity analysis was done to examine the robustness of the conclusions.
\end{abstract}

Seven studies met the eligibility criteria. No report adhered to all the principles. Major threats to validity of the conclusions included potential bias in analysis in all the studies, and lack of adjustment for baseline imbalances in four. Inadequate reporting of adverse effects hindered risk-benefit analysis. Sensitivity analysis showed that the numbers of patients withdrawn from analysis were enough to invalidate the conclusions.

It is concluded that the available evidence is not strong enough to support a routine use of dexamethasone in acute bacterial meningitis. Further research is needed to determine the effect of a policy to use dexamethasone early in the management of suspected acute bacterial meningitis. Future studies should adopt a pragmatic approach, be methodologically rigorous, and meticulously measure the risk as well as the benefit of this policy.

\section{(F Neurol Neurosurg Psychiatry 1995;59:31-37)}

Keywords: meningitis; randomised controlled trials; meta-analysis; dexamethasone

Despite better antimicrobial agents and advances in techniques of medical intensive care the mortality and long term morbidity for patients with bacterial meningitis remain substantial. In developed countries meningitis caused by the three most common aetiological bacteria, Streptococcus pneumoniae, Neisseria meningitidis, and Haemophilus influenzae type b (Hib) has fatality rates of $15.3 \%, 7 \cdot 5 \%$, and $3 \cdot 8 \%$ respectively. A further $2 \cdot 5 \%$ to $27 \cdot 7 \%$ of survivors have long term sequelae. ${ }^{1}$ The mortality and sequelae are more common in developing countries than in developed countries. $^{2-4}$

Based on current understanding of the pathophysiology of bacterial meningitis ${ }^{5}$ and results from animal studies, ${ }^{6}$ randomised controlled trials have been conducted to find out whether the use of dexamethasone as an adjunct treatment of acute bacterial meningitis improves survival or neurological outcome. ${ }^{7-12}$ The results are ambiguous and have led to differences of opinion among experts. ${ }^{13}$ Two meta-analyses have been published on the subject, ${ }^{14}{ }^{15}$ but both have received criticism. ${ }^{16}$ Neither of these systematically looked at the methodological shortcomings of the studies or evaluated the internal validity and the generalisable nature of the findings. ${ }^{17}$

The purpose of this study is to determine through a methodological appraisal of evidence $^{1718}$ the answer to the question, "Does dexamethasone adjunctive therapy in acute bacterial meningitis do more good than harm when used under routine circumstances?". In this endeavour we take a "management" or "pragmatic" approach rather than an "explanatory" one. Schwartz and Lellouch" were the first to discuss differences between the two approaches. The objective of the explanatory approach is to determine whether one treatment does more good than harm when used in ideal circumstances, whereas the objective of a management approach is to decide whether one treatment does more good than harm when used under ordinary conditions. Positive results with a management approach have implications for immediate treatment policy whereas ones with the explanatory approach do not. In this context, beneficial effects of dexamethasone in acute bacterial meningitis promise to be greater if it is given early, preferably before the antimicrobial $^{1112}$ and, therefore, treatment with dexamethasone should commence as soon as there are reasonable grounds for suspecting acute bacterial meningitis without waiting for confirmation of diagnosis. This policy will entail subjecting some patients without acute bacterial meningitis to the risks of dexamethasone, probably without any benefit. We examine whether there is evidence to support this policy. 
We have selected studies that use dexamethasone because it is the most studied steroid and is easily available and affordable. Its use is associated, however, with risk of adverse effects (see later). Therefore, its role in the management of acute bacterial meningitis needs to be critically appraised before any general recommendation is made. In an attempt to evaluate the internal validity and generalisable nature of the findings in the clinical trials of dexamethasone in acute bacterial meningitis we conducted a structured appraisal of the scientific quality of the studies. Each of the published trials was examined for adherence to well accepted methodological principles and the impact of non-adherence on the validity of the results was assessed.

\section{Methods}

To be included in this analysis, a study had to meet all of the following criteria: (1) it should be published in a journal indexed in Index Medicus in or after 1966 in English; (2) it should be a randomised concurrently controlled trial, and (3) it should use dexamethasone as an adjunct to antimicrobials in patients with community acquired acute bacterial meningitis.

To give this review broad applicability studies on patients of all age groups were included as acute bacterial meningitis occurs at all ages.

\section{BIBLIOGRAPHY DEVELOPMENT}

Citations of eligible studies were located from five sources: (1) a Medline computer search with CD-ROM disks (CD Plus OVID system) for the period from 1966 to May 1994 . $\mathrm{MeSH}$ subject headings of meningitis, clinical trials, and dexamethasone were used. All the headings were exploded to make the search comprehensive. Subsequently, the headings were combined to focus on relevant papers. (2) A computer search of Current Contents (Clinical Practice) from April 1994 to May 1994 using text words of meningitis, controlled trials, therapy, steroids, dexamethasone. (3) Issues of Neurological clinics and Paediatric/Medical Clinics of North America in Infectious Diseases/Paediatric Neurology, and issues of Infectious Diseases Clinics of North America from 1988 to April 1994. (4) Reference lists of eligible articles identified from the preceding sources. (5) Reference lists of the chapters on bacterial meningitis in textbooks of medicine, paediatrics, and neurology.

\section{METHODOLOGICAL PRINCIPLES AND RATING} ADHERENCE TO THEM

The studies were reviewed for adherence to the methodological principles described next. From methodological guidelines recommended for studying treatment ${ }^{17}$ 18 20-22 $^{2}$ the following key principles were considered most suited to the purpose of this paper. The adherence to the principles was rated as adequate, inadequate, or unclear. The rationale for selecting or omitting certain criteria is outlined.

WELL DEFINED ELIGIBILITY CRITERIA

For the results of trials to be evaluated, applied, and confirmed, investigators should precisely describe who were included in the study. Eligibility criteria allow the readers to assess the generalisable nature of the results and help understand whether the population in the various studies is similar. This is important when results from a number of studies are combined together.

\section{CREDIBLE RANDOMISATION PROCESS}

Randomisation is the essence of randomised clinical trials. If properly implemented, it removes investigator bias in the allocation of treatment to subjects, tends to produce study groups comparable with respect to known and unknown confounding variables, and allows valid application of statistical tests. If the mechanics of randomisation do not receive careful attention, however, the entire process can easily be compromised, thus invalidating any of the advantages of using it. There have been instances of tampering with the process and some processes like sealed envelopes are more prone to tampering than others, such as a telephone based system. ${ }^{23}$ Therefore, we assessed the reports for description of the randomisation process and whether the process adopted was tamper proof.

\section{APPROPRIATE CONTROL TREATMENT}

For the eligibility criteria the test treatment in the study had to be antimicrobial(s) plus dexamethasone compared with the antimicrobial alone. As the intervention is only an adjunct treatment, it was considered important to have as the control treatment an appropriate antimicrobial which corresponds to that used and recommended for use in general practice. Results that are obtained with non-recommended control treatment may not be acceptable for general use, particularly because the intervention of interest is only an adjunct form of treatment.

\section{CHOICE OF OUTCOME MEASURES AND TIMING} OF ASSESSMENT

Measures of outcome should be clinically relevant and should correspond to the purpose of the study. Clinically relevant outcomes in bacterial meningitis are mortality and permanent sequelae. The timing of assessment of sequelae is important because several studies have shown that the resolution of sequelae is time dependent. ${ }^{124}$ Most of the sequelae resolve by the end of three months but some require as long as a year. ${ }^{24}$ Therefore, we considered assessment at one year postrandomisation as the ideal, but one at three months as acceptable. We considered the following as the most relevant outcomes in this disorder: (a) death, (b) hearing loss: the most common sequelae, (c) neurological sequelae (other than hearing loss), and (d) neuropsychological (mental) impairment. Other more proximal outcomes such as duration of fever, CSF sugar, protein, 
and lactate concentrations or CSF sterilisation were not considered adequate because they are substitute end points, not meaningful for the patients.

\section{UNBIASED (BLINDED) OUTCOME} MEASUREMENT

Bias in outcome measurement in drug trials is usually controlled by blinding the patients as well as the outcome evaluators to the treatment assignment. The care givers should also be blinded to avoid any differential cointervention. We assessed whether the patients and outcome evaluators were blinded to the treatment assignment in the studies. If not, then death was the only outcome considered to have been measured unbiased. Arguably bias due to cointervention cannot be ruled out even with death as an outcome, but in acute bacterial meningitis, the scope for cointervention influencing the outcome is limited.

\section{BASELINE COMPARABILITY OF PROGNOSTIC FACTORS OR ADJUSTED ANALYSIS}

Randomisation is no guarantee that the important prognostic factors will be equally distributed in the two treatment arms. Imbalances in the distribution of such factors can confound the results, unless adjusted analysis is done to control confounding. We inspected the tables in the studies giving distribution of the factors in the two groups and assessed whether stratified or multivariate analysis was done to adjust for the imbalance(s), if any.

\section{UNBIASED ANALYSIS}

In accordance with our management approach we considered the analysis on "intention to treat" basis as the most unbiased analysis. Accordingly, no withdrawals on grounds of ineligibility or dropouts were considered legitimate. If authors did withdraw patients on these grounds, they were required to: (a) describe the precautions (for example, prior specification, blinded adjudication) that were taken to avoid introducing bias in the decisions to withdraw; $(b)$ to provide results of intention to treat analysis alongside their efficacy analysis to assure that the results are not sensitive to this approach. If intention to treat analysis was not done but adequate details were provided, we performed the analysis and examined whether conclusions changed. If adequate details to permit intention to treat analysis were not reported, we examined the robustness of the conclusions by performing a sensitivity analysis with the worst case scenario. The worst case scenario assumes that all patients with unknown outcome in the dexamethasone group did not survive or survived with sequelae (treatment failure) and those in the placebo group survived without sequelae (treatment success). If the conclusions remained unchanged with this scenario, then we considered the evidence as firm for the management question. Considering that individual studies may not have power to sustain the extreme assumptions of the worst case scenario, we combined the results to determine whether the summary estimate favoured the use of dexamethasone. We did not perform the analysis with the best case scenario because the results are obvious with the six studies out of seven being positive and this approach would not tell us whether the evidence is firm.

\section{MEASUREMENT OF ADVERSE EFFECTS}

Dexamethasone is a potentially harmful drug. Its use as an adjunctive treatment in cerebral malaria has been shown to be deleterious in randomised controlled trials. ${ }^{2526}$ Its use in intracerebral haemorrhage is also associated with increased risk of adverse effects. ${ }^{27}$ Therefore, measurement of adverse effects of dexamethasone was ascertained in all the studies.

\section{RATIONALE FOR EXCLUSION OF SOME}

METHODOLOGICAL PRINCIPLES

Some important methodological principles, ${ }^{20}$ such as compliance, contamination, cointervention, quality control, and monitoring have been excluded from the list of probes because the nature of the disease in question required all the studies to plan a brief intervention given under supervision and in all except one the care providers were masked. Sample size of the studies was not explicitly examined as this is an issue of precision of effect estimate, not of validity.

\section{Results}

The literature search yielded 17 reports of which only seven ${ }^{7-12}$ met the eligibility criteria (one paper ${ }^{8}$ contained reports of two trials). A list of the remaining 11 articles may be obtained from one of us (KP). The reasons for exclusions were study design (non-randomised control trial) and use of steroids other than dexamethasone. The adherence of the eligible studies to the methodological principles (table 1) and the impact of nonadherence on the conclusions are described next.

\section{WELL DEFINED ELIGIBILITY CRITERIA}

Whereas all the studies reported their exclusion criteria; none described the inclusion criteria explicitly. This may have a bearing on inadvertent inclusion of some patients who turned out to have a different diagnosis and had to be censored subsequently in all the studies. None of the reports described the referral pattern, method of recruitment of patients, number and kind of patients found ineligible, and those found eligible but nonconsenting. This makes it difficult to judge how the cases gravitated from the community to the study and to whom the results of the trials are generalisable. It remains unclear whether any selection bias was present in the studies.

\section{CREDIBLE RANDOMISATION PROCESS}

All the reports carried insufficient details of the randomisation process and failed to assure that bias in treatment allocation was 
Table 1 Adherence of the studies to methodological principles

\begin{tabular}{|c|c|c|c|c|c|c|c|}
\hline $\begin{array}{l}\text { Methodological } \\
\text { probes used }\end{array}$ & $\begin{array}{l}\text { Belsey } \\
\text { et al }\end{array}$ & $\begin{array}{l}\text { Lebel et al }{ }^{8} \\
\text { (study 1) }\end{array}$ & $\begin{array}{l}\text { Lebel et al } \\
\text { (study 2) }\end{array}$ & $\begin{array}{l}\text { Lebel } \\
\text { et al }\end{array}$ & $\begin{array}{l}\text { Girgis } \\
\text { et al }\end{array}$ & $\begin{array}{l}\text { Odio } \\
\text { et al }\end{array}$ & $\begin{array}{l}\text { Schaad } \\
\text { et al }\end{array}$ \\
\hline $\begin{array}{l}\text { Appropriate inclusion } \\
\text { criteria }\end{array}$ & 0 & 0 & 0 & 0 & 0 & 0 & 0 \\
\hline $\begin{array}{l}\text { Appropriate exclusion } \\
\text { criteria }\end{array}$ & + & + & + & + & + & + & - \\
\hline $\begin{array}{l}\text { Method of patient } \\
\text { recruitment }\end{array}$ & - & - & - & - & - & - & - \\
\hline $\begin{array}{l}\text { Credible } \\
\text { randomisation process }\end{array}$ & 0 & 0 & 0 & 0 & 0 & 0 & 0 \\
\hline $\begin{array}{l}\text { Appropriate control } \\
\text { treatment }\end{array}$ & - & - & + & - & - & + & + \\
\hline $\begin{array}{l}\text { Appropriate choice of } \\
\text { outcome measures and } \\
\text { timing of assessment }\end{array}$ & - & + & + & - & - & + & + \\
\hline $\begin{array}{l}\text { Unbiased outcome } \\
\text { measurement }\end{array}$ & + & 0 & 0 & 0 & - & 0 & + \\
\hline $\begin{array}{l}\text { Baseline } \\
\text { comparability of } \\
\text { prognostic factors, } \\
\text { or adjusted analysis }\end{array}$ & - & + & - & - & - & - & + \\
\hline Unbiased analysis & - & - & - & - & - & - & - \\
\hline $\begin{array}{l}\text { Adequate description } \\
\text { of adverse effects }\end{array}$ & 0 & - & - & - & - & + & - \\
\hline
\end{tabular}

$+=$ Good/adequate $0=$ unclear/partial $;-=$ inadequate.

eliminated. Some of the reported methods were more liable to bias than others. Use of a predesigned randomisation chart (for example, Girgis et $a l^{10}$ ) clearly shows the treatment assignment for the next patient to the investigator and thus can bias him in deciding whether the patient should be entered into the trial. Computer generated numbers used by Lebel et al, ${ }^{89}$ Odio et $a l,{ }^{11}$ and Schaad et al ${ }^{12}$ are less liable to bias provided that the eligibility is determined before the treatment assignment and the assignment is done by a person otherwise not involved in the study or by a central facility in contact through a telephone. It is not clear from the reports whether such an arrangement was used in any of the studies.

\section{APPROPRIATE CONTROL TREATMENT}

Four of the studies ${ }^{7 \text { (study } 1 \text { ) } 910}$ used a control treatment that is unacceptable in general practice. Lebel et $a l^{8 \text { (study 1) } 9}$ used cefuroxime and Girgis et $a l^{10}$ used drugs given intramuscularly, both of which are not recommended by experts. ${ }^{12} 16$ One study ${ }^{7}$ was carried out in 1969 when the currently recommended drugs were not available. Only three studies $^{8(\text { study 2) } 1112}$ used control treatment (intravenous ceftriaxone and cefotaxime) which is widely acceptable today.

APPROPRIATE MEASURES, TIMING, AND BLINDING OF OUTCOME ASSESSMENT

Deaths, deafness, and neurological sequelae were reported in all the studies. All except two $^{1012}$ reported neuropsychological sequelae as well but as means (SD) rather than as frequencies and hence could not be combined with deaths or other sequelae for reanalysis. The relevant outcome measures were adequately defined and assessed in four studies $^{81112}$ but blinding of the assessors of hearing at and after the three month follow up examinations was discontinued in three. ${ }^{811}$ Most of the reports ${ }^{7910}$ did not define the outcomes clearly. Another conspicuous error in the choice of outcomes for analysis was the lack of appreciation of the hierarchical nature of the outcomes under consideration. For example, death precludes other outcomes and severe deafness precludes proper assessment of mental functions. Therefore, death occupies the highest position in the hierarchy of outcomes and should be combined with sequelae whenever they are analysed. Comparing sequelae among survivors alone is an invalid comparison because deaths may be non-random and unequally distributed in the two groups and the survivors in the two groups being compared may no more be similar in baseline prognostic factors. Also the number of patients with one or more severe sequelae (plus the number of deaths) should form the basis of the main analysis rather than the number of sequelae, because two sequelae may occur in the same patient or one sequelae may preclude the assessment of the other (as pointed out earlier). All the reports ignored these considerations in their analysis.

\section{BASELINE COMPARABILITY OF PROGNOSTIC} FACTORS OR ADJUSTED ANALYSIS

All the studies presented tables comparing the baseline features of the experimental and control group and all except one ${ }^{7}$ recorded that there was no significant difference between the two groups. But a closer examination of the tables showed that in four other studies, ${ }^{8(\text { study 2) }}$ 9-11 there were considerable differences in at least one important prognostic variable between the two groups. Two studies $^{1011}$ had a shorter duration of symptoms before admission and two ${ }^{8(\text { study } 2)} 9$ had a higher proportion of patients who had previously taken antibiotics in the dexamethasone group; both factors are associated with a favourable outcome. One study ${ }^{8(\text { study } 2)}$ had a difference in the duration of illness favouring the placebo group. None of the studies, however, used stratified or multivariate analysis to adjust for these differences. Therefore, the possibility of substantial confounding cannot be ruled out. One study ${ }^{10}$ provided enough details on mortality (not on sequelae) to allow a stratified analysis. The analysis (table 2) shows that the conclusions of the study favouring 
Table 2 Stratified analysis of study by Girgis, et al ${ }^{10}$

\begin{tabular}{|c|c|c|c|c|c|c|}
\hline \multirow{2}{*}{$\begin{array}{l}\text { Strata according to } \\
\text { duration of symptoms } \\
\text { before admission (days) }\end{array}$} & \multicolumn{2}{|c|}{ Dexamethasone group } & \multicolumn{2}{|c|}{ Control group } & \multirow[b]{2}{*}{ Odds ratio } & \multirow[b]{2}{*}{$95 \% C I$} \\
\hline & Deaths & Total & Deaths & Total & & \\
\hline $\begin{array}{l}\text { Less than } 2 \text { days } \\
2 \text { to } 4 \text { days } \\
\text { More than } 4 \text { days } \\
\text { Pooled Mantel-Haenszel }{ }^{28} \text { estimator }\end{array}$ & $\begin{array}{l}4 \\
8 \\
8\end{array}$ & $\begin{array}{r}32 \\
128 \\
50\end{array}$ & $\begin{array}{r}4 \\
24 \\
14\end{array}$ & $\begin{array}{r}23 \\
152 \\
44\end{array}$ & $\begin{array}{l}0.68 \\
0.39 \\
0.42 \\
0.43\end{array}$ & $\begin{array}{l}0 \cdot 15-3 \cdot 06 \\
0 \cdot 19-0 \cdot 82 \\
0 \cdot 16-1 \cdot 08 \\
0 \cdot 25-0 \cdot 74\end{array}$ \\
\hline
\end{tabular}

Crude estimate of odds ratio $=0.49$; test for homogeneity $\left(\right.$ Breslow-Day $\left.{ }^{29}\right) \chi^{2}(2 \mathrm{df}) 0.55(\mathrm{P}=0.97)$.

dexamethasone are not affected by the baseline differences, although the magnitude of effect is reduced by $10 \%$. Other reports do not provide enough details to allow an adjusted analysis to be carried out.

\section{ANALYSIS}

None of the reports presented an intention to treat analysis. All the reports had postrandomisation withdrawals from the analysis. The withdrawn proportions constituted more than $10 \%$ of all the randomised patients in five studies ${ }^{7811} 12$ and ranged from $3 \%$ to $26 \%$. Major reasons for withdrawal were ineligibility and losses to follow up but also included inability to complete the dexamethasone course due to its adverse effects or early death. None of the reports indicated that the decisions to withdraw were made without the knowledge of outcome or treatment assignment of the patients and reasons for doing so were not stated in advance. We attempted to reconstruct an intention to treat analysis for each study but only one study ${ }^{10}$ presented enough details to permit the same for death as an end point. The analysis showed a statistically significant $(P=0.01)$ reduction in mortality in the dexamethasone group (21/225 $(9.3 \%))$ compared with the control group $(43 / 245(17 \cdot 5 \%))$. A clinically relevant question is whether the additional patients so saved are left with unacceptable morbidity. Enough details were not provided to answer this question.

The other studies did not provide information on the number of patients withdrawn from each treatment group on the grounds of ineligibility and the final outcome in the patients withdrawn. It was thus not possible to construct an intention to treat analysis. We therefore conducted a sensitivity analysis assuming that the patients withdrawn on grounds of ineligibility were equally distributed between the two groups and taking the worst case scenario for the reasons stated. Table 3 presents the results. It is clear that the results are sensitive to the extreme assumptions and do not provide a robust conclusion. The number of patients withdrawn from analysis are sufficient to invalidate the conclusions. The summary odds ratio of this analysis also does not clearly favour dexamethasone or placebo.

\section{MEASUREMENT OF ADVERSE EFFECTS}

The adverse effects of dexamethasone were not clearly reported in any study. One study ${ }^{12}$ reported that adverse effects occurred rarely, but frequencies were not given. Another reported that two patients had gastrointestinal bleeding but other adverse effects such as secondary infections were not mentioned. ${ }^{8}$ It is not clear from the reports whether adverse effects were carefully recorded. Thus it is impossible to know whether the risk-benefit ratio of using dexamethasone is in its favour.

\section{Discussion}

The results show that none of the reports on dexamethasone adhere to all the methodological principles of a sound controlled clinical trial from the perspective of management. The methodological principles described are important in facilitating the interpretation of internal validity and generalisable nature of the trial results. Finding non-adherence to the principles makes the conclusions of the studies questionable.

INTERNAL VALIDITY

Inadequate description of the randomisation

Table 3 Sensitivity analysis (worst case scenario)

\begin{tabular}{|c|c|c|c|c|c|c|}
\hline \multirow[b]{2}{*}{$\begin{array}{l}\text { Authors (year) } \\
\text { of study }\end{array}$} & \multirow[b]{2}{*}{$\begin{array}{l}\text { Total } \\
\text { No of } \\
\text { patients } \\
\text { enrolled }\end{array}$} & \multirow[b]{2}{*}{$\begin{array}{l}\text { No } \\
\text { withdrawn } \\
\text { from } \\
\text { analysis (\%) }\end{array}$} & \multicolumn{2}{|c|}{$\begin{array}{l}\text { No of patients in each group } \\
\text { after reassignment }\end{array}$} & \multirow[b]{2}{*}{$\begin{array}{l}P \\
\text { value }\end{array}$} & \multirow[b]{2}{*}{$\begin{array}{l}\text { Odds ratio } \\
(95 \% C I) \dagger\end{array}$} \\
\hline & & & $\begin{array}{l}\text { Dexamethasone } \\
\text { group } \\
\text { (failure*/total) }\end{array}$ & $\begin{array}{l}\text { Control } \\
\text { group } \\
\text { (failure/total) }\end{array}$ & & \\
\hline $\begin{array}{c}\text { Belsey et al } \\
1969\end{array}$ & 102 & $16(16)$ & $9 / 51$ & $13 / 51$ & 0.33 & $0.62(0.21-1.8)$ \\
\hline $\begin{array}{r}\text { Lebel et al } \\
\text { (study } 1)\end{array}$ & 108 & $28(26)$ & $21 / 55$ & $17 / 53$ & 0.5 & $1.3(0.55-3.12)$ \\
\hline $\begin{array}{l}\text { Lebel et al }{ }^{8} \\
\quad(\text { study } 2)\end{array}$ & 114 & $19(17)$ & $10 / 58$ & $5 / 56$ & $0 \cdot 19$ & $2 \cdot 12(0 \cdot 6-7 \cdot 8)$ \\
\hline $\begin{array}{l}\text { Lebel et al } \\
\text { Odio et al }{ }^{11} \\
\text { Girgis et al }{ }^{10} \\
\text { Schaad et al }{ }^{12} \\
\text { Summary odds }\end{array}$ & $\begin{array}{r}61 \\
120 \\
470 \\
138 \\
\% \mathrm{CI})\end{array}$ & $\begin{aligned} & 2(3) \\
& 21(18) \\
& 41(9) \\
& 23(17)\end{aligned}$ & $\begin{array}{l}2 / 31 \\
14 / 61 \\
39 / 225 \\
13 / 70\end{array}$ & $\begin{array}{c}3 / 30 \\
8 / 59 \\
50 / 245 \\
9 / 68\end{array}$ & $\begin{array}{l}0.62 \\
0.18 \\
0.4 \\
0.53\end{array}$ & $\begin{array}{l}0.62(0.06-5.1) \\
1.89(0.66-5.5) \\
0.81(0.5-1.33) \\
1.48(0.60-3.68) \\
1.06(0.79-1.44)\end{array}$ \\
\hline
\end{tabular}

$\star$ Failure $=$ death or sequelae $; \mathrm{CI}=95 \%$ confidence interval 
process and lack of maintenance of blinding throughout the course of the study raise questions about the internal validity of the results. Even if we assume that no substantial bias was introduced in randomisation or outcome measurement, the validity of the results of all the studies is threatened by bias in analysis. May et $\mathrm{al}^{30}$ state that "bias can easily be introduced and should always be suspected if subjects are withdrawn . . . after randomisation." Withdrawing subjects from analysis puts the three cardinal features (given earlier) of randomisation in jeopardy. Even if the subjects remaining in the two groups are comparable in the known prognostic factors, the same may not remain true for the unknown prognostic factors. We discuss next how the three reasons of withdrawal in the studies analysed are likely to introduce bias in the results. The three reasons of withdrawal are ineligibility, inability to complete the dexamethasone course, and losses to follow up.

The withdrawals on the grounds of ineligibility may have been influenced by a knowledge of the outcome. Bias due to such withdrawals is illustrated by the Anturane reinfarction trial. ${ }^{31}$ In the placebo group there was little difference in the mortality of patients who were withdrawn and those who were analysed $(12 \cdot 1 \% v 10.9 \%)$. This was by contrast with the sulfinpyrazone group, in which mortality was almost three times greater in patients who were withdrawn than in those who were retained $(26.3 \% v 9 \cdot 1 \%)$. This obviously introduces bias and the study has been criticised for this. ${ }^{32}$ May et $a l^{30}$ and Freidman et $a l^{23}$ advocate that after randomisation, no withdrawals should be allowed and the primary analysis should include all subjects enrolled. Subgroup analyses on the basis of baseline data, including eligibility state, may be done. If the conclusions from analyses agree, then interpretation of subgroup analysis is easier. Should the results differ, one must be cautious in drawing firm conclusions from subgroups. In general, the analysis with all the enrolled subjects (intention to treat basis) should be emphasised.

Excluding patients because of inability to complete the course of dexamethasone due to, say, upper gastrointestinal bleeding clearly introduces bias in favour of the drug. Patients developing such bleeding might have been sicker and might have had poor outcome. Excluding these from the analysis gives undue advantage to dexamethasone by systematically excluding sicker patients from its arm.

Withdrawals due to losses to follow up raises doubt whether the overall result might have been altered if the missing information had been available. Firm conclusions can still be made if the sensitivity analysis shows that assigning the most optimistic (in conclusively negative studies) or pessimistic (in conclusively positive studies) values for the missing data does not affect them. This was not so in any of the studies analysed here. At best, the conclusions reported in the studies would apply if and only if one could exclude nonacute bacterial meningitis cases before starting dexamethasone, but obviously this is not possible in routine clinical practice.

Internal validity of four of the studies is also threatened by lack of adjustment in the analysis for differences in the baseline prognostic factors.

\section{GENERALISABLE NATURE OF THE RESULTS}

Results of the studies cannot be generalised to all patients with acute bacterial meningitis because only one study ${ }^{10}$ included adults and some used unacceptable control treatment (cefuroxime ${ }^{8 \text { (study 1) } 9}$ drugs given intramuscularly $\left.{ }^{10}\right)$. More importantly the results of studies lacking internal validity cannot be generalisable. Another important consideration in assessing the generalisable nature of a treatment in acute bacterial meningitis is the epidemiological and clinical setting. The mix of patients seen in one country may be different from that in another country. For example, the report from Egypt ${ }^{10}$ shows that less than $20 \%$ of patients are admitted within 48 hours of onset of symptoms whereas the average duration of illness in Dallas and Costa Rica was 24 to 36 hours. Correspondingly the Egyptian study ${ }^{10}$ reported a greater proportion of comatose patients $(64 \%)$ and a higher mortality $(20 \%$ in its control group) compared with a mortality of $1 \%$ to $2 \%$ in the Dallas ${ }^{8}$ and Costa Rican ${ }^{11}$ studies. The Egyptian study also showed that the aetiological organism of acute bacterial meningitis is an important determinant of outcome and effect of dexamethasone. Meningococcal meningitis, $\mathrm{Hib}$ meningitis, and pneumococcal meningitis manifested case fatality rates of $7 \%, 33 \%$, and $41 \%$ respectively and the corresponding risk differences due to dexamethasone were $3 \%$, $6 \%$, and $27 \%$ respectively. This indicates that any attempt to generalise the policy of dexamethasone treatment should take the aetiological range and epidemiology into account.

\section{COMMENTS ON PREVIOUS META-ANALYSES}

It is clear from the foregoing methodological appraisal that the studies published so far lack the internal validity that is a basic requirement for a valid conclusion from a meta-analysis. At best, these studies provide a basis for a management trial. Further, these meta-analyses combined "apples with oranges" because different antibiotics were used in the various trials. For example, the antibiotics used for meningitis in the various trials were chloramphenicol plus sulfadiazine, ${ }^{7}$ ampicillin plus chloramphenicol, ${ }^{10}$ cefuroxime, ${ }^{8(\text { study } 1)} 9$ ceftriaxone, ${ }^{8(\text { study 2) } 12}$ or cefotaxime. ${ }^{11}$ The outcome of treatment in acute bacterial meningitis depends clearly on the antibiotic used. Therefore, the pooling of the results from these studies has been criticised by experts. ${ }^{1633}$

\section{Conclusion}

The results of this appraisal show that the available evidence is not strong enough to support a routine use of dexamethasone in acute bacterial meningitis. There is a need for more research on the role of dexamethasone 
in the treatment of acute bacterial meningitis. Organisers of such studies should consider the methodological issues described in this paper. The future studies should take a management approach rather than an explanatory one. Until further studies are reported, firm and general recommendations about the role of dexamethasone in acute bacterial meningitis cannot be made.

We acknowledge support of INCLEN Inc, Philadelphia, USA for providing an INCLEN fellowship to Dr Kameshwar Prasad for a period of 15 months during which this work was done.

1 Baraff LJ, Lee SI, Schriger DL. Outcomes of bacterial meningitis in children: a meta-analysis. Pediatr Infect Dis $f$ 1993;12:389-94

2 Habib RG, Girgis NI, Yassin MW, Laughlin LW, Sippe JE, Edman DC. Hearing impairment in meningococcal meningitis. Scand $\mathcal{f}$ Infect Dis 1979;114:806-9.

3 Munoz O, Benitz-Diaz L, Martinez MC, Guiscafre H. Hearing loss after Hemophilus influenzae meningitis: follow-up study with auditory brainstem potentials. An Otol Rhinol Laryngol 1983;92:272-5.

4 Jiang ZD, Liu XY, Wu YY, Zheng MS, Liu HC. Longterm impairments of brain and auditory functions of children recovered from purulent meningitis. Dev Med Child Neurol 1990;32:473-80.

5 Saez-Llorens X, Ramilo O, Mustafa MM, Mertsola J McCracken GH Jr. Molecular pathophysiology of bacterial meningitis: current concepts and therapeutic implications. F Pediatr 1990;116:671-84.

6 Tauber MG, Shibl AM, Haekbarth CJ, Larrick JW, Sande MA. Antibiotic therapy, endotoxin concentration in cerebrospinal fluid and brain edema in experimental Escherichia coli meningitis in rabbits. F Infect Dis 1987 156:456-62.

7 Belsey MA, Hoffpauir CW, Smith MH. Dexamethasone in the treatment of acute bacterial meningitis: the effect of study desion on the interpretation of results. Pediatrics $1969 ; 44: 503-13$

8 Lebel MH, Freji BJ, Syrogiannopoulos GA, Chrane DF, Hoyt MJ, Stewart SM, et al. Dexamethasone therapy for placebo-controlled trials. $N$ Engl $f$ Med 1988;319: placebo-con

9 Lebel MH, Hoyt MJ, Waagner DC, Rollins NK, Finitzo $\mathrm{T}$, McCracken GH Jr. Magnetic resonance imaging and dexamethasone therapy for bacterial meningitis. Am Dis Child 1989;143:301-6.

10 Girgis NI, Farid Z, Mikhail IA, Sultan Y, Kilpatrick ME. Dexamethasone treatment for bacterial meningitis in children and adults. Pediatr Infect Dis f 1989;8:848-51.

11 Odio CM, Faingezicht I, Paris M, Nassar M, Baltodano A, Rogers J, et al. The beneficial effect of early dexamethasone administration in infants and children with bacterial meningitis. N Engl ₹ Med 1991;324:1525-31.
12 Schaad UB, Lips U, Gnehm HE, Blumberg A, Heinzer I, Wedgwood J. Dexamethasone therapy for bacterial meningitis in children. Lancet 1993;342:457-61.

13 McGowan JE Jr., Chesney PJ, Crossley KB, LaForce FM. Guidelines for the use of systemic corticosteroids in the management of selected infections. F Infect Dis 1992; 165:1-13.

14 Geiman BJ, Smith AL. Dexamethasone and bacterial meningitis: a meta-analysis of randomised controlled meningitis: a meta-analysis of rand

15 Havens PL, Wendelberger KJ, Hoffman GM, Lee MB, Chusid MJ. Cortico-steroids as adjunctive therapy in bacterial meningitis: a meta-analysis of clinical trials. $\mathrm{Am}$ $\mathcal{f}$ Dis Child 1989;143:1051-55.

16 Havens PL. Meta-analysis redux-steroids and meningitis revisited [editorial]. West $\mathcal{F}$ Med 1992;157:84-6.

17 Oxman AD, Guyatt GH. Guidelines for reading literature reviews. Can Med Assoc $\mathcal{F} 1988 ; 138: 697-703$.

18 Chalmers TC, Smith H, Blackburn B, et al. A method for assessing the quality of a randomized controlled trial. Controlled Clinical Trials 1981;2:31-49.

19 Schwartz D, Lellouch J. Explanatory and pragmatic attitudes in therapeutic trials. Fournal of Chronic Diseases 1967;20:637-48.

20 Meinert CL. Clinical trials. Design, conduct and analysis. New York: Oxford University Press, 1986.

21 Fletcher RH, Fletcher SW, Wagner EH. Clinical epidemiology: the essentials. Baltimore: Williams and Wilkins, 1988

22 Sackett DL, Haynes RB, Guyatt GH, Tugwell P. Clinical epidemiology: a basic science for clinical medicine. Toronto: Little, Brown and Co, 1991.

23 Friedman LM, Furberg CD, Demets DL. Fundamentals of clinical trials. 2nd ed. Littleton: PSG Publishing Co Inc, 1985.

24 Pomeroy SL, Holmes SJ, Dodge PR, Feigin RD. Seizures and other neurologic sequelae of bacterial meningitis in children. N Engl FMed 1990;323:1651-7.

25 Warrell DA, Looareesuwan S, Warrell MJ, Kasensarn P, Intaraprasert $R$, Bunnag $D$, Harinasuta $T$. Dexamethasone proves deleterious in cerebral malaria: a double-blind trial in 100 comatose patients. $N$ Engl $\mathscr{f}$ double-blind trial in 10

26 Hoffman SL, Rustama D, Punjabi NH, Surampaet B, Sanjaya B, Dimpudus AJ, et al. High-dose dexamethasone in quinine treated patients with cerebral malaria: a double-blind, placebo-controlled trial. $\mathcal{F}$ Infect Dis 1988; 158:325-31.

27 Poungvarin N, Bhoopat W, Viriyavejakul A, et al. Effects of dexamethasone in primary supratentorial intracerebral hemorrhage. N Engl $\mathcal{F}$ Med 1987;316:1229-33.

28 Mantel N, Haenszel W. Statistical aspects of the analysis of data from retrospective studies of disease. $₹ \mathrm{Natl}$ Cancer Inst 1959;22:719-48.

29 Breslow NE, Day NE. Analysis of case-control studies. Vol 1. Statistical methods of cancer research. Lyon: IARC Scientific Publications; 1980:122-59.

30 May GS, Demets DL, Friedman LM, Furberg C, Passamani E. The randomized clinical trial: bias in analysis. Circulation 1981;64:669-73.

31 The Anturane Reinfarction Trial Research Group. Sulfinpyrazone in the prevention of sudden death after myocardial infarction. N Engl f Med 1980;302:250-6.

32 Temple R, Pledger GW. The FDA's critique of the Anturane Reinfarction Trial. N Engl f Med 1980;303: 1488-92.

33 Meningitis Working party of the British Paediatric Immunology and Infectious Disease Group. Should we use dexamethasone in meningitis? Arch Dis Child 1992; 67:14 